\title{
Timing of cranial vault remodeling in nonsyndromic craniosynostosis: a single-institution 30-year experience
}

\author{
*Alan F. Utria, MD,1 Joseph Lopez, MD, MBA, ${ }^{1}$ Regina S. Cho, BS,, Gerhard S. Mundinger, MD," \\ George I. Jallo, MD, ${ }^{2}$ Edward S. Ahn, MD, ${ }^{2}$ Craig Vander Kolk, MD, ${ }^{1,3}$ and \\ Amir H. Dorafshar, MBChB'
}

Departments of ${ }^{1}$ Plastic and Reconstructive Surgery and ${ }^{2}$ Neurosurgery, Johns Hopkins Hospital; and ${ }^{3}$ Division of Plastic Surgery, Mercy Medical Center, Baltimore, Maryland

OBJECTIVE Due to the changing properties of the infant skull, there is still no clear consensus on the ideal time to surgically intervene in cases of nonsyndromic craniosynostosis (NSC). This study aims to shed light on how patient age at the time of surgery may affect surgical outcomes and the subsequent need for reoperation.

\begin{abstract}
METHODS A retrospective cohort review was conducted for patients with NSC who underwent primary cranial vault remodeling between 1990 and 2013. Patients' demographic and clinical characteristics and surgical interventions were recorded. Postoperative outcomes were assessed by assigning each procedure to a Whitaker category. Multivariate logistic regression analysis was performed to determine the relationship between age at surgery and need for minor (Whitaker I or II) versus major (Whitaker III or IV) reoperation. Odds ratios (ORs) for Whitaker category by age at surgery were assigned.
\end{abstract}

RESULTS A total of 413 unique patients underwent cranial vault remodeling procedures for NSC during the study period. Multivariate logistic regression demonstrated increased odds of requiring major surgical revisions (Whitaker III or IV) in patients younger than 6 months of age (OR 2.49,95\% Cl 1.05-5.93), and increased odds of requiring minimal surgical revisions (Whitaker I or II) in patients older than 6 months of age (OR 2.72, 95\% Cl 1.16-6.41).

CONCLUSIONS Timing, as a proxy for the changing properties of the infant skull, is an important factor to consider when planning vault reconstruction in NSC. The data presented in this study demonstrate that patients operated on before 6 months of age had increased odds of requiring major surgical revisions.

http://thejns.org/doi/abs/10.3171/2016.5.PEDS1663

KEY WORDS craniosynostosis; cranial vault remodeling; nonsyndromic; sutures; synostosis; craniofacial surgery

$\mathrm{C}$ RANIOSYNOSTOSIS refers to the premature fusion of single or multiple cranial sutures in the infant skull leading to calvarial growth restrictions and predictable compensatory deformations. ${ }^{19}$ In addition to the aesthetic deformations, craniosynostosis has been shown to affect brain morphology with resultant neurological sequelae. , $^{8,22}$ The incidence is approximately 1 in 2500 births and can be subclassified as single- versus multiplesuture fusion and syndromic versus nonsyndromic cases. ${ }^{18}$ Syndromic cases are characterized by the presence of several other dysmorphologies of the trunk, face, or extremities, which present in well-defined patterns..$^{5}$ The pathophysiology behind craniosynostosis is not well understood. Surgical correction remains the mainstay of treatment, but there are many aspects of management that remain controversial, such as the ideal timing of surgical intervention. ${ }^{7,22}$ It has been proposed that earlier intervention is more advantageous due to the plasticity of the infant skull and the ability to prevent rises in intracranial pressure. ${ }^{9}$ Proponents of delayed intervention favor waiting until a later age, as there is a decreased likelihood of resynostosis, and studies suggest that cranial vault remodeling outcomes are more predictable. ${ }^{16,20,26}$ Due to the lack of consensus and evidence, timing of surgical procedures continues to be guided by surgeon preference and patient presentation.

The purpose of this study was to examine the Johns Hopkins Hospital experience with nonsyndromic craniosynostosis (NSC) and attempt to shed some light on the ideal timing for surgical intervention. Based on the experience of the senior surgeon (A.H.D.), we hypothesize that "early" surgical intervention would be associated with major surgical revisions, demonstrated by higher Whitaker scores. The specific aims of this study were the following: 1) to identify all NSC patients who underwent primary cra-

ABBREVIATIONS NSC = nonsyndromic craniosynostosis; $\mathrm{OR}=$ odds ratio.

SUBMITTED February 16, 2016. ACCEPTED May 23, 2016.

INCLUDE WHEN CITING Published online August 12, 2016; DOI: 10.3171/2016.5.PEDS1663.

* Drs. Utria and Lopez contributed equally to this work. 
nial vault remodeling between 1990 and 2013 at a single multidisciplinary institution; 2) to obtain pre-, intra-, and postoperative data retrospectively from this cohort; and 3) to assess whether an association exists between timing of surgery and major or minor surgical revisions.

\section{Methods \\ Study Design/Sample}

After approval was obtained from the Johns Hopkins School of Medicine Institutional Review Board, retrospective chart review was conducted for patients with NSC who underwent cranial vault remodeling between 1990 and 2013 at the Johns Hopkins Hospital. These patients underwent surgery because of 1) clinical findings of an abnormal head shape consistent with craniosynostosis, and/or 2) radiological evidence of a fused cranial suture, and/or 3) clinical or radiological impression of elevated intracranial pressures. All patients were selected based on the following inclusion criteria: 1) age between 1 month and 18 years, 2) confirmed diagnosis of NSC, and 3) no history of previous cranial vault remodeling. Exclusion criteria included: 1) absence of follow-up, 2) primary cranial vault reconstruction performed at another institution, and 3) suspected positional plagiocephaly. Of note, timing of surgery was not determined by institutional protocols or clinical pathways. Timing was largely dependent on age at presentation to our tertiary referral center.

\section{Predictor/Outcome Variables}

Demographic information including sex, race, and age at time of surgery was recorded for all patients who qualified for inclusion in the study. Other patient characteristics, including suture involvement, medical comorbidities, surgical procedure, postoperative complications, length of hospital stay, last follow-up, and need for surgical revisions were also collected. Postoperative outcomes were assessed by assigning each primary cranial vault procedure to a Whitaker category ${ }^{27}$ based on follow-up descriptions by the neurosurgical and plastic surgery teams. Category I signified an excellent result requiring no additional surgery, Category II signified soft tissue and lesser bone contouring requiring minor revisions, Category III signified major alternative osteotomies or bone grafting requiring more extensive revisions, and Category IV signified the need for major surgical revision, essentially duplicating the original surgery. Whitaker Categories I and II and Whitaker Categories III and IV were combined for the analysis to increase statistical power. In cases in which planned 2-stage remodeling was perfored only the first procedure was included in the analysis. Patients were grouped by age at the time of surgery as follows: age $<6$ months and age $>6$ months.

\section{Statistical Analysis}

Statistical analysis was subsequently performed to assess for any associations between age at time of surgery and postoperative outcomes as recorded by Whitaker category. Potential confounders such as patient characteristics, surgical procedure, and comorbidities were stratified by age at time of surgery and were compared using a chi- square analysis. Mean length of stay and patient followup time were compared using the Student t-test analysis. Univariate logistic regression was then used to look for associations between age at time of surgery and Whitaker category. All patient characteristics that showed significance at alpha $<0.05$ (2-tailed) in chi-square analysis were then assessed against Whitaker category using univariate logistic regression. Variables that were significant at alpha $<0.05$ (2-tailed) in univariate logistic regression were included as covariates in multivariate modeling. A subanalysis by age group was also performed to assess for any association between surgical procedure and Whitaker category. Lastly, multivariate logistic regression was used to determine odds ratios (ORs) for minor versus major surgical revisions based on age at the time of surgery. The covariates that were used in this model include coronal suture fusion, the presence of hydrocephalus, CSF shunt, use of hardware during the surgical procedure, and anterior and posterior cranial vault remodeling. A $p$ value $<0.05$ was considered statistically significant. All de-identified data were iteratively entered into a statistical database (Stata/MP software, v. 12, StataCorp) for analysis.

\section{Results}

\section{Patient Characteristics}

During the 23-year study period, 545 unique patients underwent cranial vault remodeling procedures for NSC. Of these patients, 42 were lost to follow-up, 37 had undergone their primary cranial reconstructions at other institutions, and 53 had suspected positional plagiocephaly. Therefore, only 413 patients met the specified criteria and were included in the analysis (Fig. 1).

Of the 413 patients, $254(62 \%)$ were male, $338(82 \%)$ were white, 52 (13\%) were African American, and 8 (2\%) were Hispanic. Fusion of a single suture was observed in 282 patients $(68 \%)$, fusion of 2 sutures was observed in 33 patients $(8 \%)$, and fusion of 3 or more sutures was observed in 29 patients (7\%). Suture involvement was not specified in 69 patients (17\%). The most common isolated suture fusion was sagittal synostosis, present in 142 patients $(30 \%)$, followed by metopic synostosis, which was present in 81 patients (17\%). Of the multiple-suture synostoses the most common presentation was sagittal and metopic suture fusion, present in 14 patients (3\%). Cranial vault remodeling procedures were categorized as anterior in 175 patients (42\%), posterior in $90(22 \%)$, and subtotal in $37(9 \%)$ and as multiple strip craniectomies in 107 (26\%). The average length of stay was 5 days and the average duration of follow-up was 5 years (Table 1). Among the operating neurosurgeons and plastic surgeons, chi-square analysis revealed no statistically significant differences with respect to timing of surgery or outcomes of surgery. Helmet therapy as an adjunct for open calvarial modeling was not part of our standard protocol.

\section{Surgical Timing, Procedure, and Outcomes}

One hundred forty-six patients (35\%) of those who underwent cranial vault remodeling were under the age of 6 months at the time of surgery; 267 patients $(65 \%)$ were older than 6 months (Table 2). The outcome of the proce- 

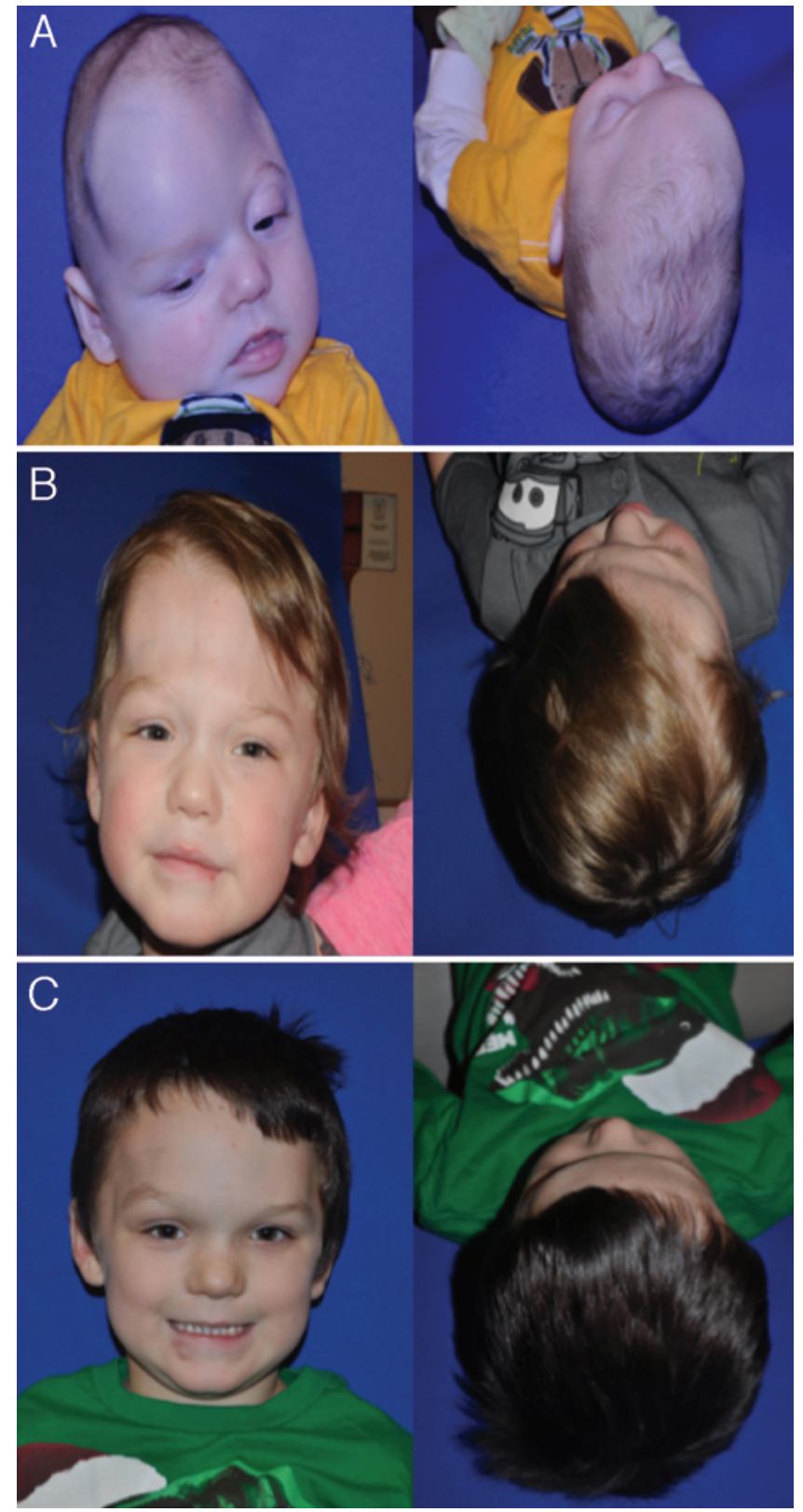

FIG. 1. Example of a case in which reoperation was required. A: Photographs obtained at presentation showing a male infant with nonsyndromic multiple-suture craniosynostosis. Anterior cranial vault reconstruction was performed when he was 5 months old. B: Follow-up photographs obtained when the boy was 2 years of age, demonstrating turricephaly, requiring reoperation. C: Follow-up photographs obtained when the boy was 4 years old demonstrating good results. Figure is available in color online only.

dure was classified as Whitaker Category I in 289 cases (70\%), Category II in 65 cases (16\%), Category III in 13 cases (3\%), and Category IV in 46 cases (11\%) (Fig. 2).

\section{Association Between Surgical Timing and Whitaker Category}

Whitaker categories were grouped together into no or only minor revision required (Whitaker I/II) and major revision required (III/IV). Univariate logistic regression
TABLE 1. Patient characteristics by age at surgery*

\begin{tabular}{|c|c|c|c|c|}
\hline \multirow[b]{2}{*}{ Characteristic } & \multicolumn{2}{|c|}{ Age at Surgery } & \multirow{2}{*}{$\begin{array}{c}\text { All } \\
\text { Patients } \\
(n=413)\end{array}$} & \multirow[b]{2}{*}{$\begin{array}{c}p \\
\text { Value }\end{array}$} \\
\hline & $\begin{array}{l}<6 \text { Mos } \\
(n=146)\end{array}$ & $\begin{array}{c}>6 \text { Mos } \\
(n=267)\end{array}$ & & \\
\hline \multicolumn{5}{|l|}{ Demographics } \\
\hline Male sex & $97(66)$ & $157(59)$ & $254(62)$ & 0.127 \\
\hline White race & $135(92)$ & $203(76)$ & $338(82)$ & $<0.001$ \\
\hline African American race & $8(5)$ & $44(16)$ & $52(13)$ & 0.001 \\
\hline Other race & $3(2)$ & $20(7)$ & $23(6)$ & 0.021 \\
\hline \multicolumn{5}{|l|}{ Time points } \\
\hline $\begin{array}{l}\text { Mean length of stay } \\
\text { in days }\end{array}$ & 3.91 & 5.2 & 4.7 & 0.267 \\
\hline Mean follow-up in yrs & 4.7 & 4.99 & 4.89 & 0.508 \\
\hline \multicolumn{5}{|l|}{ Suture involvement† } \\
\hline Metopic & $23(16)$ & $81(30)$ & $104(25)$ & 0.001 \\
\hline Sagittal & $113(77)$ & $75(28)$ & $188(46)$ & $<0.001$ \\
\hline Lambdoid & $22(15)$ & $16(6)$ & $38(9)$ & 0.002 \\
\hline Coronal & $29(20)$ & $55(21)$ & $84(20)$ & 0.859 \\
\hline Cloverleaf & $5(3)$ & $6(2)$ & $11(3)$ & 0.477 \\
\hline \multicolumn{5}{|l|}{ No. of sutures involved } \\
\hline 1 & $102(70)$ & $180(67)$ & $282(68)$ & 0.609 \\
\hline 2 & $17(12)$ & $16(6)$ & $33(8)$ & 0.043 \\
\hline 3 or more & $20(14)$ & $9(3)$ & $29(7)$ & $<0.001$ \\
\hline Unspecified & $7(5)$ & $62(23)$ & $69(17)$ & $<0.001$ \\
\hline \multicolumn{5}{|l|}{ Comorbidities } \\
\hline Hydrocephalus & $3(2)$ & $34(13)$ & $37(9)$ & $<0.001$ \\
\hline Chiari malformation & $2(1)$ & $13(5)$ & $15(4)$ & 0.069 \\
\hline CSF shunt & $3(2)$ & $24(9)$ & $27(7)$ & 0.006 \\
\hline
\end{tabular}

* Values are numbers of cases (\%) unless otherwise indicated. As shown, the majority of patients in this cohort were white males with few comorbidities. A substantial proportion of the patients had involvement of the sagittal $(46 \%)$ and/or metopic (25\%) suture. Most of the patients $(68 \%)$ had single-suture involvement.

$\dagger$ Included multiple patients with involvement of more than 1 suture $(n=62)$.

analysis of age at time of primary surgery against Whitaker category (Table 3 ) demonstrated that patients operated on before 6 months of age had a decreased odds (OR 0.57, $95 \%$ CI $0.33-0.99)$ of requiring no revision or only minor revisions compared with patients operated on after 6 months of age. Results of the multivariate analysis (Table 3) showed age less than 6 months at time of surgery was associated with increased odds (OR 2.49, 95\% CI 1.055.93 ) of requiring major revision surgery. Similarly, age less than 6 months was associated with decreased odds (OR $0.37,95 \%$ CI $0.16-0.86$ ) of requiring no or only minor revisions (Table 3 ).

\section{Discussion}

Much progress has been made since 1888 when the first attempt at surgical correction of craniosynostosis was performed. ${ }^{11}$ However, despite these advances, there is still no clear approach to the management of craniosynostosis. Authors of various studies have come to advocate for different surgical techniques and timing of intervention but a general 
TABLE 2. Procedure characteristics by patient age at surgery*

\begin{tabular}{|c|c|c|c|c|}
\hline \multirow[b]{2}{*}{ Characteristic } & \multicolumn{2}{|c|}{ Age at Surgery } & \multirow{2}{*}{$\begin{array}{c}\text { All } \\
\text { Patients } \\
(n=413)\end{array}$} & \multirow[b]{2}{*}{$\begin{array}{c}\mathrm{p} \\
\text { Value }\end{array}$} \\
\hline & $\begin{array}{l}<6 \text { Mos } \\
(n=146)\end{array}$ & $\begin{array}{l}>6 \text { Mos } \\
(n=267)\end{array}$ & & \\
\hline \multicolumn{5}{|l|}{ Procedure } \\
\hline Multiple strip craniectomies & $101(70)$ & $6(2)$ & $107(26)$ & 0.000 \\
\hline $\begin{array}{l}\text { Subtotal cranial recon- } \\
\text { struction }\end{array}$ & $6(4)$ & $31(12)$ & $37(9)$ & 0.011 \\
\hline $\begin{array}{l}\text { Anterior vault reconstruc- } \\
\text { tion }\end{array}$ & $22(15)$ & $153(57)$ & $175(42)$ & 0.000 \\
\hline $\begin{array}{l}\text { Posterior vault reconstruc- } \\
\text { tion }\end{array}$ & $15(10)$ & $75(28)$ & $90(22)$ & 0.000 \\
\hline \multicolumn{5}{|l|}{ Materials used } \\
\hline Wire & $17(12)$ & $132(49)$ & $149(36)$ & 0.000 \\
\hline Hardware & $16(11)$ & $130(49)$ & $146(35)$ & 0.000 \\
\hline Resorbables & $17(12)$ & $110(41)$ & $127(31)$ & 0.000 \\
\hline
\end{tabular}

* Values are numbers of cases (\%) unless otherwise indicated. As shown, the most commonly performed procedures by age group were multiple strip craniectomies ( 6 months of age) and anterior cranial vault remodeling ( $>6$ months of age). The use of hardware, wires, and resorbables was less common in patients under 6 months of age.

consensus has yet to be reached. ${ }^{4,7,21,26}$ Given that the infant calvaria undergoes significant changes within the 1st year of life, timing of surgical intervention is of particular interest. When deciding on the appropriate time for surgical intervention, the surgeon must consider the plasticity of the infant calvaria, the need to support rigid fixation, and the calvaria's ability to heal osseous defects, while not delaying treatment and jeopardizing neurological function..$^{9,15,18}$

In this study we sought to examine our institution's experience treating 413 consecutive cases of NSC to determine the optimal timing for surgical intervention. Pa- tients were grouped by age at the time of surgery $(<6$ months, $>6$ months) and outcomes were assessed using Whitaker categories. ${ }^{27}$ The age cutoff of 6 months was chosen according to the changing properties of the infant calvaria. ${ }^{15,18,20,25}$ Our analysis revealed that our institution's rate of major revision surgery was $14 \%(\mathrm{n}=59)$. This is comparable to recent studies that have demonstrated rates ranging from $6 \%$ to $19.5 \% \cdot 13,17,20,28$ Overall, we classified $289(70 \%)$ outcomes as Whitaker I, $65(16 \%)$ as Whitaker II, $13(3 \%)$ as Whitaker III, and $46(11 \%)$ as Whitaker IV. When analyzed by patient age, our results demonstrated that patients who were operated on before 6 months of age had a higher likelihood of requiring major revision surgery (Table 3). This finding was statistically significant in the multivariate analysis that controlled for confounders such as procedure type and disease severity (i.e., hydrocephalus). More specifically, we found that $18 \%$ of patients ( $\mathrm{n}=$ 27) who were operated on when they were younger than 6 months had outcomes that were classified as Whitaker III/ IV compared with $12 \%$ of patients $(n=32)$ who were operated on when they were older than 6 months. This is in accordance with similar age-related rates of reoperation that were described by Seruya et al..$^{20}$ There are several hypotheses that could account for the finding of better outcomes in patients who are operated on at a later age. We postulate that following bone remodeling surgery, the rapid, exponential brain growth that occurs during the 1st year of life affects the final shape of the calvaria. Therefore, very early calvarial vault remodeling, such as before 6 months of age, may lead to unpredictable surgical outcomes. Others believe that before 6 months of age, an infant's calvaria lacks the capacity to hold shape or allow for effective use of rigid fixation, therefore potentially increasing the likelihood of future major surgical revisions. ${ }^{16,18}$ Although the biological/physiological drivers behind the increased likelihood of major revision surgery are still unclear, our analysis

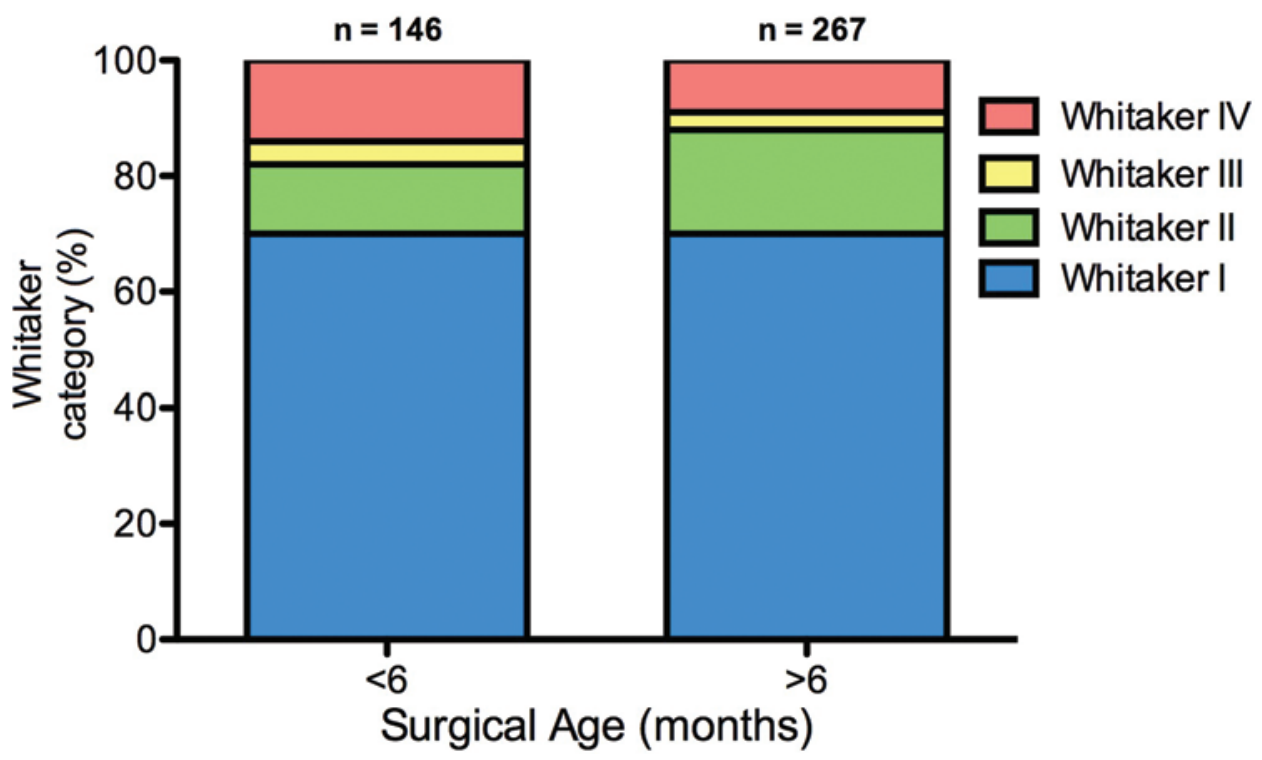

FIG. 2. Whitaker category by patient age at surgery. As shown, the results of surgery in the majority of patients $(71 \%)$ in our cohort were classified as Whitaker I. Comparison of results in patients operated on when they were younger than 6 months with results in patients operated on when they were older than 6 months showed that the proportion of outcomes classified as Whitaker I/II was greater in the latter group ( $82 \%$ vs $88 \%$, respectively, $p=0.047)$. Figure is available in color online only. 
TABLE 3. Results of univariate and multivariate logistic regression analyses for outcome of surgery performed when patients were younger than 6 months of age

\begin{tabular}{lllll}
\hline \multicolumn{1}{c}{ Analysis \& Outcome } & OR & SE & p Value & $95 \% \mathrm{Cl}$ \\
\hline Univariate logistic regression* & & & & \\
\hline Whitaker I/II & 0.57 & 0.16 & $0.049 \dagger$ & $0.33-0.99$ \\
\hline Whitaker III/IV & 1.67 & 0.47 & 0.073 & $0.95-2.91$ \\
\hline Multivariate logistic regression $\ddagger$ & & & & \\
\hline Whitaker I/II & 0.37 & 0.16 & $0.022 \dagger$ & $0.16-0.86$ \\
\hline Whitaker III/IV & 2.49 & 1.10 & $0.039 \dagger$ & $1.05-5.93$ \\
\hline
\end{tabular}

\footnotetext{
* As shown, patients operated on before 6 months of age had decreased odds of being classified as Whitaker I/II compared to patients operated on after 6 months of age.

† Significant at alpha $<0.05$.

$\ddagger$ As shown, age less than 6 months at time of surgery was associated with increased odds of requiring major revision surgery (Whitaker III/IV) and decreased odds of requiring no or minor revisions (Whitaker I/II). The following variables were included as covariates in the multivariate analysis: presence of coronal suture fusion, presence of hydrocephalus, presence of a CSF shunt, use of hardware during the surgical procedure, and anterior and posterior cranial vault remodeling.
}

does suggest that a delayed approach may be preferable. Our analysis revealed that patients 6 months of age or older at surgery were significantly more likely to require no revisions or only minor revision surgery (Whitaker I/II) than patients who were younger than 6 months of age at the time of initial surgery (Table 3).

In summary, our results support that operating on patients less than 6 months of age increases their likelihood of requiring major revision surgery, whereas operating after 6 months of age decreases that likelihood. Although it has been proposed that patients with more severe disease undergo earlier surgery and that this may impact final surgical outcomes, we were able to indirectly control for severity of disease by accounting for the presence of hydrocephalus or a CSF shunt as covariates. We then hypothesized that perhaps a) the particular suture involved, b) the type of surgical procedure performed, and c) the surgical team performing the surgical procedure, over the course of the 30-year experience at our institution, would affect our results; however, when we performed subgroup analyses of these variables, we were not able to achieve statistical significance. We believe that the low power in our subanalysis precluded determination of which individual factors significantly affected our results. We therefore believe that our results should not be used in isolation to determine the optimal age of surgical intervention in every type of craniosynostosis, but should be used in the wider context to note that if surgical intervention is performed for craniosynostosis before 6 months of age, one should expect a higher likelihood of requiring major revision surgery. Clearly, large multi-institutional studies will be required to determine the impact of age of initial surgery with regard to suture type and surgical technique.

Our study has several limitations that merit consideration. First, we did not assess neurocognitive outcomes. While aesthetic function is very important and can play an important role in the child's psychological well-being, the avoidance of neurological sequelae from increased in- tracranial pressure must take precedence. ${ }^{14}$ Our analysis demonstrates that operating when patients are older produces excellent results and decreases the need for reoperation. However, our study did not explore whether surgical delay impacts neurodevelopment, and there is a paucity of studies that have directly analyzed neurodevelopment with regard to age at surgical intervention. Furthermore, the studies that currently exist are conflicting; Hashim et al. ${ }^{9}$ advocate for intervention before 6 months of age, while Arnaud et al. ${ }^{1}$ believe that intervention before 1 year of age is sufficient to avoid any neurological sequelae. While these studies are important contributions to the literature and should be considered when determining surgical management, they remain controversial at this time. ${ }^{6,23,29}$

The data, however, are further complicated by research by Backeljauw et al. ${ }^{2}$ that has demonstrated that general anesthesia might negatively affect neurocognitive outcomes in pediatric populations. This finding suggests that optimizing the surgical intervention to perform a single definitive procedure, minimizing the need for reoperation and repeat general anesthesia (as well as the other risks associated with surgery), may result in better neurocognitive outcomes. However, we strongly believe that cranial vault remodeling should be performed regardless of patient age if there is a high risk for negative neurological sequelae (i.e., raised intracranial pressure). To ascertain that the timing of surgical correction is neurologically optimal, further research will be needed. ${ }^{3,24}$

Another limitation was our inability to control for confounders that may have contributed to delayed surgical care, such as national and international referral patterns, patient choice, and surgeon preference. In terms of surgeon preference, however, our surgeons largely followed similar practice patterns, and there were no significant differences in surgical timing or outcomes between surgeons. Additionally, we were not able to identify suture involvement in approximately 69 patients who were included in the analysis; however, since we sought to determine whether timing affected surgical outcomes irrespective of suture type or number of sutures involved, we decided to include these patents in the analysis. Furthermore a subanalysis of these patients showed they may have had more severe disease compared with other patients in the same age category. Thus, excluding these patients from the analysis would have introduced a selection bias to our results by eliminating patients who might have had more severe disease.

Finally, our main surgical outcome metric, the Whitaker category, is a subjective assessment that is extremely useful but is limited by observer bias. Future studies should aim to incorporate objective surgical outcome measurements such as anthropometric data, thereby facilitating preoperative and postoperative cephalometric evaluations.

\section{Conclusions}

The optimal timing for surgical intervention in NSC remains controversial with respect to both functional and aesthetic outcomes. It remains unclear what role timing of surgical intervention plays in the neurodevelopment of the infant brain, but it has been suggested that intervening before 12 months of age is sufficient to avoid any nega- 
tive sequelae. Our data demonstrate that patients operated on before 6 months of age have an increased likelihood of requiring major surgical revisions, whereas operating after 6 month of age decreases that likelihood, suggesting that there is benefit in waiting for surgical intervention for $\mathrm{NSC}$, at least with respect to major reoperation rates.

\section{References}

1. Arnaud E, Meneses P, Lajeunie E, Thorne JA, Marchac D, Renier D: Postoperative mental and morphological outcome for nonsyndromic brachycephaly. Plast Reconstr Surg 110:6-13, 2002

2. Backeljauw B, Holland SK, Altaye M, Loepke AW: Cognition and brain structure following early childhood surgery with anesthesia. Pediatrics 136:e1-e12, 2015

3. Bradley JP, Lee JC: Discussion: the effects of whole-vault cranioplasty versus strip craniectomy on long-term neuropsychological outcomes in sagittal craniosynostosis. Plast Reconstr Surg 134:502-503, 2014

4. Cohen SR, Pryor L, Mittermiller PA, Meltzer HS, Levy ML, Broder KW, et al: Nonsyndromic craniosynostosis: current treatment options. Plast Surg Nurs 28:79-91, 2008

5. Derderian C, Seaward J: Syndromic craniosynostosis. Semin Plast Surg 26:64-75, 2012

6. Derderian CA, Heppner C, Cradock MM, Woo AS, Patel KB, Smyth MD, et al: The effects of whole-vault cranioplasty versus strip craniectomy on long-term neuropsychological outcomes in sagittal craniosynostosis. Plast Reconstr Surg 136:114e-115e, 2015

7. Foster KA, Frim DM, McKinnon M: Recurrence of synostosis following surgical repair of craniosynostosis. Plast Reconstr Surg 121:70e-76e, 2008

8. Garza RM, Khosla RK: Nonsyndromic craniosynostosis. Semin Plast Surg 26:53-63, 2012

9. Hashim PW, Patel A, Yang JF, Travieso R, Terner J, Losee JE, et al: The effects of whole-vault cranioplasty versus strip craniectomy on long-term neuropsychological outcomes in sagittal craniosynostosis. Plast Reconstr Surg 134:491-501, 2014

10. Kapp-Simon KA, Speltz ML, Cunningham ML, Patel PK, Tomita T: Neurodevelopment of children with single suture craniosynostosis: a review. Childs Nerv Syst 23:269-281, 2007

11. Lane LC: Pioneer craniectomy for relief of mental imbecility due to premature sutural closure and microcephalus. JAMA 18:49-50, 1892

12. Lee HQ, Hutson JM, Wray AC, Lo PA, Chong DK, Holmes $\mathrm{AD}$, et al: Analysis of morbidity and mortality in surgical management of craniosynostosis. J Craniofac Surg 23:1256-1261, 2012

13. McCarthy JG, Glasberg SB, Cutting CB, Epstein FJ, Grayson BH, Ruff G, et al: Twenty-year experience with early surgery for craniosynostosis: I. Isolated craniofacial synostosis-results and unsolved problems. Plast Reconstr Surg 96:272283, 1995

14. Ozgur BM, Aryan HE, Ibrahim D, Soliman MA, Meltzer HS, Cohen SR, et al: Emotional and psychological impact of delayed craniosynostosis repair. Childs Nerv Syst 22:16191623,2006

15. Paige KT, Vega SJ, Kelly CP, Bartlett SP, Zakai E, Jawad AF, et al: Age-dependent closure of bony defects after frontal orbital advancement. Plast Reconstr Surg 118:977-984, 2006

16. Panchal J, Uttchin V: Management of craniosynostosis. Plast Reconstr Surg 111:2032-2049, 2003

17. Pearson GD, Havlik RJ, Eppley B, Nykiel M, Sadove AM: Craniosynostosis: a single institution's outcome assessment from surgical reconstruction. J Craniofac Surg 19:65-71, 2008
18. Persing JA: MOC-PS(SM) CME article: management considerations in the treatment of craniosynostosis. Plast Reconstr Surg 121 (4 Suppl):1-11, 2008

19. Persing JA, Jane JA, Shaffrey M: Virchow and the pathogenesis of craniosynostosis: a translation of his original work. Plast Reconstr Surg 83:738-742, 1989

20. Seruya M, Oh AK, Boyajian MJ, Posnick JC, Myseros JS, Yaun AL, et al: Long-term outcomes of primary craniofacial reconstruction for craniosynostosis: a 12-year experience. Plast Reconstr Surg 127:2397-2406, 2011

21. Shah MN, Kane AA, Petersen JD, Woo AS, Naidoo SD, Smyth MD: Endoscopically assisted versus open repair of sagittal craniosynostosis: the St. Louis Children's Hospital experience. J Neurosurg Pediatr 8:165-170, 2011

22. Shipster C, Hearst D, Somerville A, Stackhouse J, Hayward $\mathrm{R}$, Wade A: Speech, language, and cognitive development in children with isolated sagittal synostosis. Dev Med Child Neurol 45:34-43, 2003

23. Speltz ML, Birgfeld C, Starr JR, Collett B, Kapp-Simon K: The effects of whole-vault cranioplasty versus strip craniectomy on long-term neuropsychological outcomes in sagittal craniosynostosis. Plast Reconstr Surg 135:646e-647e, 2015

24. Speltz ML, Kapp-Simon K, Collett B, Keich Y, Gaither R, Cradock MM, et al: Neurodevelopment of infants with single-suture craniosynostosis: presurgery comparisons with case-matched controls. Plast Reconstr Surg 119:1874-1881, 2007

25. Utria AF, Mundinger GS, Bellamy JL, Zhou J, Ghasemzadeh A, Yang R, et al: The importance of timing in optimizing cranial vault remodeling in syndromic craniosynostosis. Plast Reconstr Surg 135:1077-1084, 2015

26. Wall SA, Goldin JH, Hockley AD, Wake MJ, Poole MD, Briggs M: Fronto-orbital re-operation in craniosynostosis. $\mathbf{B r}$ J Plast Surg 47:180-184, 1994

27. Whitaker LA, Bartlett SP, Schut L, Bruce D: Craniosynostosis: an analysis of the timing, treatment, and complications in 164 consecutive patients. Plast Reconstr Surg 80:195-212, 1987

28. Williams JK, Cohen SR, Burstein FD, Hudgins R, Boydston W, Simms C: A longitudinal, statistical study of reoperation rates in craniosynostosis. Plast Reconstr Surg 100:305-310, 1997

29. Wood BC, Proctor MR, Rogers GF: The effects of wholevault cranioplasty versus strip craniectomy on long-term neuropsychological outcomes in sagittal craniosynostosis. Plast Reconstr Surg 135:925e-926e, 2015

\section{Disclosures}

Dr. Dorafshar reports receiving indirect research support and being entitled to royalties from KLS Martin as well as receiving indirect research support from DePuy Synthes.

\section{Author Contributions}

Conception and design: Dorafshar, Utria, Lopez, Mundinger. Acquisition of data: Utria, Cho. Analysis and interpretation of data: Utria, Lopez, Cho, Mundinger. Drafting the article: Utria, Lopez, Cho. Critically revising the article: Dorafshar, Utria, Lopez, Mundinger, Jallo, Ahn, Vander Kolk. Reviewed submitted version of manuscript: Dorafshar, Utria, Lopez, Mundinger, Jallo, Ahn, Vander Kolk. Statistical analysis: Utria. Administrative/technical/material support: Dorafshar, Jallo, Ahn, Vander Kolk. Study supervision: Dorafshar.

\section{Correspondence}

Amir H. Dorafshar, Department of Plastic and Reconstructive Surgery, Johns Hopkins Hospital, JHOC 8150, 600 North Wolfe St., Baltimore, MD 21287. email: adorafs1@jhmi.edu. 